\title{
HAl: An Instructional Motion Graphic of How to Interact with People with Autism for Grade Schoolers
}

\author{
Fonita Theresia Yoliando \\ Faculty of Art \& Design, Universitas Multimedia Nusantara, Tangerang, INDONESIA \\ Email: fonita.yoliando@umn.ac.id
}

Published: 28 September 2020

\begin{abstract}
Autism Spectrum Disorder (ASD) is known as 'triad impairment' which consists of communication, interaction, and behaviour problem. They also exhibit hypersensitivities or hyposensitivities to physical sensory stimuli which affect the processing system to be overloaded and cause an uncomfortable feeling or pain. Their reactions then trigger some particular behaviors, which are considered aggressive, harmful, repetitive, and odd. The main problem is most people judge and avoid them solely based on their actions without any effort to find out the reason and learn how to interact with them properly. This one-sided stereotype most probably leads them and their family to emotional insecurities, lack of selfesteem, and rebellious tendency. While this kind of situation is mostly centralized, institutionalized, and deep rooted in society, it can be reconditioned through a small step by teaching people since their early age the appropriate way to interact with people with autism. It is essential to realize that each individual with autism is first and foremost an individual who should not be treated as invisible in society. In order to facilitate this idea, I offer HAI: An Instructional Motion Graphic of How to Interact with People with Autism for Grade Schoolers which consists of several illustrated empirical steps which can be applied in school. The instructions are suitable to interact with several specific types of ASD, such as Classic Autism and Asperger syndrome, by reason of the severity of the symptoms which enables them to live relatively normal lives in society. In other words, the main objective of this project is to encourage and assist people, especially grade schoolers to have short conversation or simple interaction with their autistic friends through practical and proper set of actions. Throughout this project, sequential exploratory design method was implemented by combining qualitative and quantitative method in the process.
\end{abstract}

Keywords: autism, interaction, instructional, motion graphic

eISSN: 2550-214X (C) 2020. The Authors. Published for Idealogy Journal by UiTM Press. This is an Open Access article distributed under the terms of the Creative Commons Attribution-NonCommercial-NoDerivatives License (http://creativecommons.org/licenses/by-nc-nd/4.0/), which permits non-commercial re-use, distribution, and reproduction in any medium, provided the original work is properly cited, and is not altered, transformed, or built upon in any way.

\section{AUTISM IN SOCIETY}

Based on the data from WHO, in 2018 the prevalence rate of people with autism is 1:160 and the number grows rapidly in the last decade (www.who.int). Autism is no longer a rare disability and occurs in people from any backgrounds, ethnics, or socioeconomic groups. The past researches indicate that the primary factor of autism is genetics which is aggravated by many other factors, such as pollution, toxic residue, animal fur, food preservative, and many others which can't be ascertained so far. Moreover, $31 \%$ of children with ASD also have intellectual disability while others are in borderline, in the average, or above the average (Autism Speaks, 2017). They mainly experience difficulties in: (1) communicating - using lots of repetitive words, having problem to start conversation with peers, showing interest only on their favourite topics, taking long time to respond a question, and unable to understand long or complex sentences, (2) interacting - lack of eye contact and expression, having different non-verbal communication like body movements, facing difficulties in showing and feeling emotions, unable to stand crowd, (3) controlling behaviours - showing an extreme interest in a particular thing beyond reasonable limits, being strict to their routines, doing a certain movement repeatedly especially when they feel nervous or stressed, being hypersensitive or hyposensitive to physical sensory stimuli like loud noise, strong odour, hot/cold temperatures, unexpected touch, and others (Santrock, 
2011). Nearly $28 \%$ of them also indicate intense repetitive movements and self-injurious behaviours, such as head banging, arm biting, and skin scratching. Those actions mostly are induced by environmental issues or sensory stimulations which cause them unpleasant sensations, pain, confusion and lead to panic attack (Caldwell, 2006). By doing a certain behaviour, their brain finds an alternative to focus on rather than their sensory distress and it calms them. As a result, it is undeniably that almost two-thirds of the children with autism between the ages of 6 and 15 have been bullied and experience depression or anxiety which affects 11-40\% of them (Autism Speaks, 2017, pp. 15-18).

There are five categories of Autism Spectrum Disorder (ASD): Classic Autism Disorder, Asperger Syndrome, Pervasive Development Disorder - No Otherwise Specified (PDD-NOS), Rett Syndrome, and Childhood Disintegrative Disorder (National Autism Centre, 2011, pp. 8). Among those five, Classic Autism Disorder and Asperger Syndrome are categorized as high-function autism which means they have a greater possibility to live independently and adapt in society since they mostly do not exhibit cognitive issue, verbal delay, or motoric problem. Even though, autism is a lifelong matter which can't be cured, it doesn't mean that their condition is hopeless, especially for people with less severe symptoms as Classic Autism and Asperger Syndrome. They are more than able to live relatively normal through an appropriate education and a supportive environment which is the duty of community members to provide such opportunities. In fact, there are many simple things that we can do for people with autism in daily life, such as changing the way we talk, act, and look at them. However, before trying to approach people with autism, an adequate understanding and knowledge are absolutely necessary in order to avoid unneeded risk in the process. Accordingly, HAI comes to provide a practical tips and tricks in interacting with people with autism, based on the perspective of professional therapist, psychologist, association, school, and affected parents. Considering autism is a spectrum, it is advisable that the instructions which are given should be adjusted to characters, preferences, and needs of each individual with autism.

\section{SEQUENTIAL EXPLORATORY DESIGN METHOD}

This research endeavours to encourage and educate people, especially grade schoolers about how to have a regular conversation or interaction with high-function autistic friends in school. In order to fulfil the research objective, sequential exploratory design method (Creswell, 2014, p. 709-714) was implemented. It consists of qualitative method as the initial step to understand and interpret the condition, followed by quantitative method as the key point to test the hypotheses and analyze the cause. Greater emphasis was placed on the qualitative method which is specifically performed on professional therapist, psychologist, association, school, and affected parents. In contrast, the target of the quantitative method was administered to school-aged children (7-11 years old). In this age, most children learn about appropriate behaviour, tolerance, respect, responsibility, and other important social skills (Rashid, 2010, pp.69). Moreover, they are starting to be able to connect logical reason with empathetical reason which are suitable as the target of this research.

\section{QUALITATIVE METHOD}

\subsection{Therapist}

Based on the interviews with a professional therapist at a therapy centre in Indonesia, Sri Rahayu, S. Psi, there are various types of therapy that can be carried out according to the characteristics and needs of each child since people with autism have different symptoms and spectrum. In general, it can be categorized into three main parts: (1) behaviour therapy/ applied behaviour analysis, (2) physical therapy/ motoric physiotherapy, and (3) speech therapy, which consists of concentration therapy, emotional therapy, cognitive therapy, self-sufficiency therapy, and social interaction therapy. She stated that through a right treatment, everyone can socialize with people with autism. They can be connoted as a car without brake, so the task of people around them is to create boundaries for them by giving rules and instructions. Most of the time, people tend to use negative words such as 'do not' or 'no' to prevent them doing things which bring out opposite effects for people with autism. The cause is their 
limitation in verbal communication which often leads to misunderstanding in their brain. In other words, those prohibited things are recorded in their brain as something that they have to do which resulted them to behave otherwise. It is suggested to use clear and straightforward instruction through exemplification or pictures which is done consistently. The rewarding method is also considered effective to improve their visual, kinesthetics, logical, and sensory ability.

\subsection{Psychologist}

In the interview session with Fransisca M. Sidabutar, M. Psi who is a consultant psychologist in paediatric clinical psychology and educational psychology, she implied that symptom of sensory hypersensitivity is probably the main cause of people's misconception toward people with autism. Having this symptom means feeling 10,000 times of smell, taste, touch, and noise more than ordinary people feel. As a result, when they try to protect themselves by ditching, refusing, flapping their hands, or being hyper, people tend to be afraid and avoid them entirely. It is undeniable that people with autism prefer to live individually because it is a comfort and safe zone for them. However, surviving in society and being independent, means they should learn to interact and communicate with people. In order to support that, it is essential to present an amicable response, like smiles and greetings. Being exposed to positive reactions and strong impressions continuously, their adaptability and social interaction skills are expected to be continuously developed. Thus, understanding and empathy will grow which eventually lead to positive changes in society.

\subsection{Association}

"Although different, people with autism are not defects, idiots, or inferior, so it is better if society can value them more", said Dunya Affan, as a parent with autistic children and also a committee of one of autism associations in Indonesia, MPATI (Masyarakat Peduli Autis Indonesia). According to the interview with her, it can be concluded that there are three main steps in campaigning autism to society: acceptance, understanding, and approach. Firstly, it is essential to accept their existence, uniqueness, capabilities, and shortcomings. By realizing that they are a potential individual who was born for a good reason, mutual respect can be built. The next step is trying to understand their world further, like knowing their hobbies, preferences, dislikes, and others. So instead of force people with autism to get out from their world instantly, it is more possible for society to immerse in their world first. Lastly, a consistent effort to communicate and interact with people with autism is needed. It should be done in stages, repeatedly, and sequentially, from the simplest things in a proper way and right timing. In conducting campaigns and outreach, MPATI focuses to provide a targeted and understandable information to specific group of society. For example, in order to socialize how to handle missing autistic children in the mall, an electronic poster or short video about the steps that must be performed by the security team was provided.

\subsection{School}

The next session was in-depth observation and interview with teachers from Mutiara Indonesia International School (1983) which consists of two types of classes, Regular Class and Brilliant Class for special needs children. If a student in Brilliant Class has improved and met the requirements, such as being able to communicate, interact, answer questions, and follow instructions, they can be moved to Regular Class. In Brilliant Class, there are five students with one teacher who performed Classical Learning System and Individual Learning System alternately. While the classical one is done by giving instruction for all students, individual system focuses in improving each student's weaknesses and strengths. Most of the time, teachers teach with short words and consistent tones to be easily captured. They often repeat questions or instructions several times then followed by providing examples in a form of pictures/ photos on paper. Leading the concentration of people with autism during class hours is the most challenging part so teachers should often approach the students' table to see what they are doing, direct them directly, and talk to them personally. In contrast, there is not much interaction among students with autism because they tend to have difficulties in starting conversation. Some students who 
still have difficulties in buying food, opening beverage cans, food boxes, tying shoelaces, and so on, were accompanied by their parents, caretaker, or shadow teachers who wait outside the classroom. During breaks, they usually spend time together with students from Regular Class who greeted and talked to them first. They also responded properly and seemed enthusiastic, especially if it is a preferable topic for them. Even though, the difference in the way of people of autism speak or behave is indisputable, it does not interfere with their interaction because other students are accustomed to it and able to accept it. This positive condition stimulates people with autism to take the liberty to ask for help, assistance, or opinion from their peers though there are still a small number of students who are not interested in interacting with them at all. Providing an intimate and mutual relationship among students, teachers, and parents are considered exceptionally beneficial for people with autism's growth and improvement.

\subsection{Parents}

In a sharing session with Mrs. Liana, she explained her experience with her son, Christopher who has high-function autism. He is a smart student, talented in music, and friendly with people. However, when he attended a private junior high school, he was changed. He had difficulties in adapting because the teachers tended to be indifferent, the classrooms were hot, stuffy, and chaotic, a rapid learning system and curriculum, also the attitude of the teacher who rebuked fiercely and loudly, even threatened with punishment. In addition, he also experienced bullying and had become a joke among his friends, for example hiding his pants during sports hours, telling him to run around if he wanted to play, even touching the genitals of his male friends with the threat of being punished if they did not. This has a huge negative impact on Christopher's psychology. He became depressed, did not want to go to school, did not want to eat, and did not express himself. Mrs. Liana stated that this situation is commonly happened to special needs children and it becomes a huge concern for the affected family. After she moved Christopher to another school which provides special program for autism with a professional teachers and trainer, Christopher becomes extremely improved in social skills, academic skills, and music skills. Regarding this, the role of people around him, especially families, teachers, trainers, and friends is very dominant in people with autism's mental and physical stability. Quoted from the interview with Ms. Liana, "Understanding, attention, affection, and hard work for autistic children is indeed needed but the most important of all is opportunity and acceptance."

\section{QUANTITATIVE METHOD}

Data collection in the form of a questionnaire was executed to 50 respondents aged 7-11 years who are grade schoolers in Indonesia, especially in Jabodetabek. Online and offline dissemination has been carried out for 14 days. The questionnaire targeted to extract children's perspective about their autistic friends and determine the media which is most suitable for them.

Of the 50 respondents, 42 grade schoolers had met with autism so that it could be said that autistic children have been very often found in daily life, both in the family, school, and society. $36 \%$ showed concern for people and $34 \%$ felt confused about how to treat and interact with them. While small numbers of them feel excited, annoyed, or afraid. From this data, many students face difficulties in treating their autistic friends because they have limited information how to interact and communicate with people with autism normally though they indicate concern and interest to some extent. In short, a set of practical instructions that can be handily applied in their school life is needed. 


\section{Grade Schoolers' Perspective about Autism}

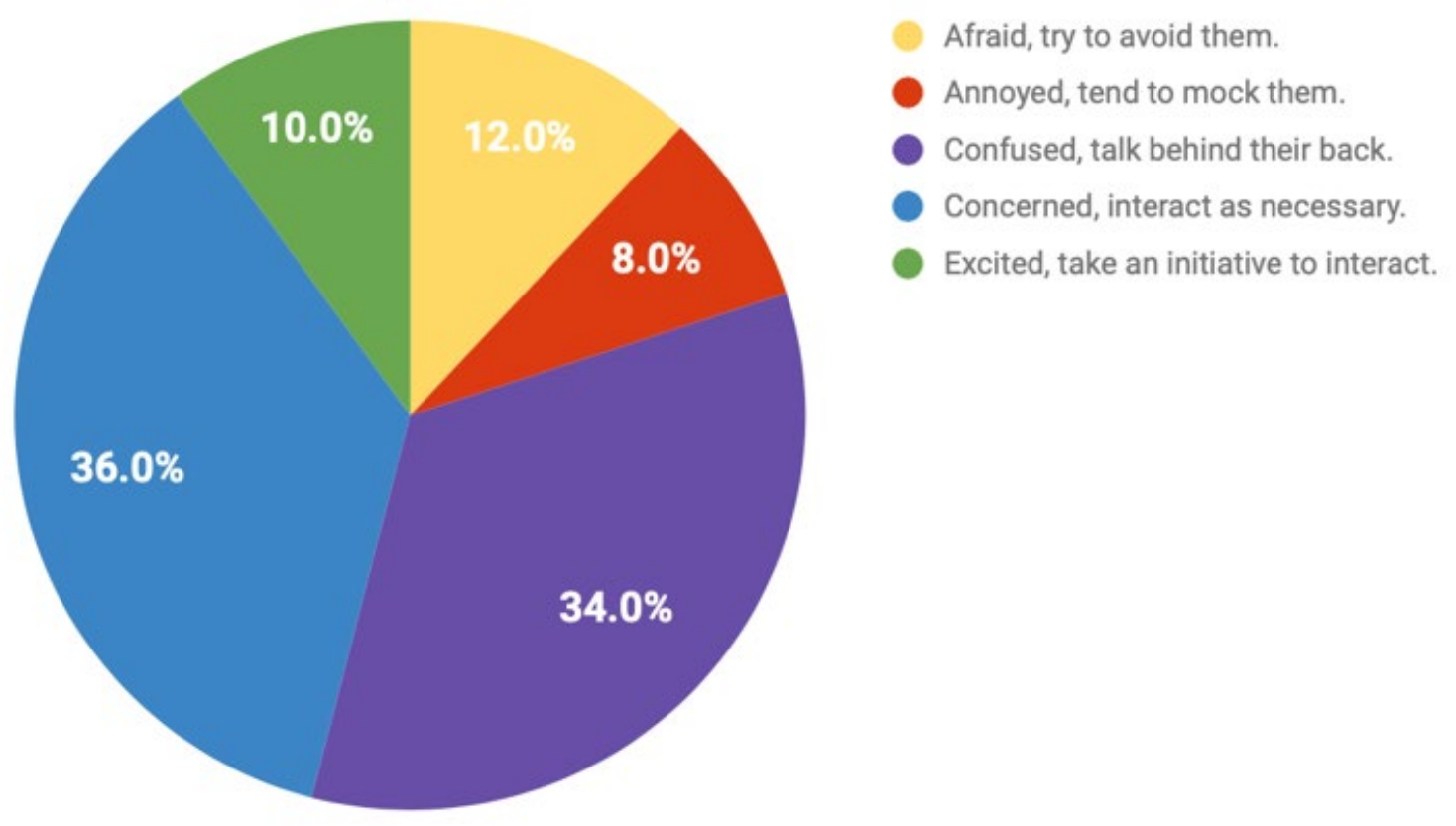

Figure 1: Questionnaire 1

\section{Media Preferences of Grade Schoolers}

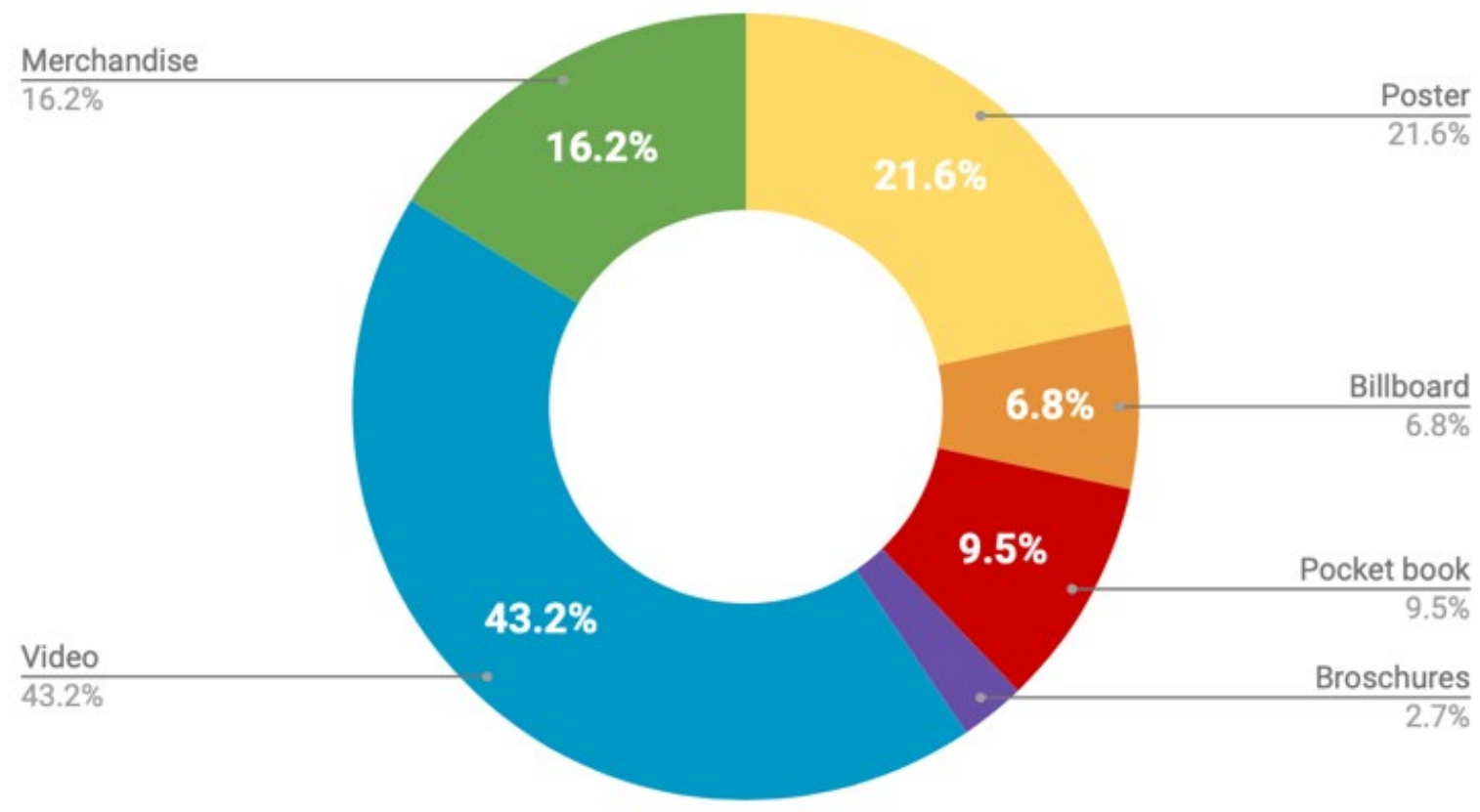

Figure 2: Questionnaire 2

The results of the questionnaire showed more than $40 \%$ respondents prefers video as their favourite media rather than printed media or merchandise. In addition, 31 respondents spent between 1-5 hours while 19 others spent more than 5-10 hours accessing the internet. From the result, the activities most often carried out by teenagers are opening social media or watching videos with a percentage of more than $40 \%$. Based on this finding, using electronic media such as online videos to reach grade schoolers as the main target is considered compatible. 


\section{CONCEPT AND DESIGN OF 'HAI'}

Having completed qualitative and quantitative method, the next step was dedicated to the concept and design development process. The findings from those research methods were extracted and concluded to be the five practical steps which became the main content of the motion graphic.

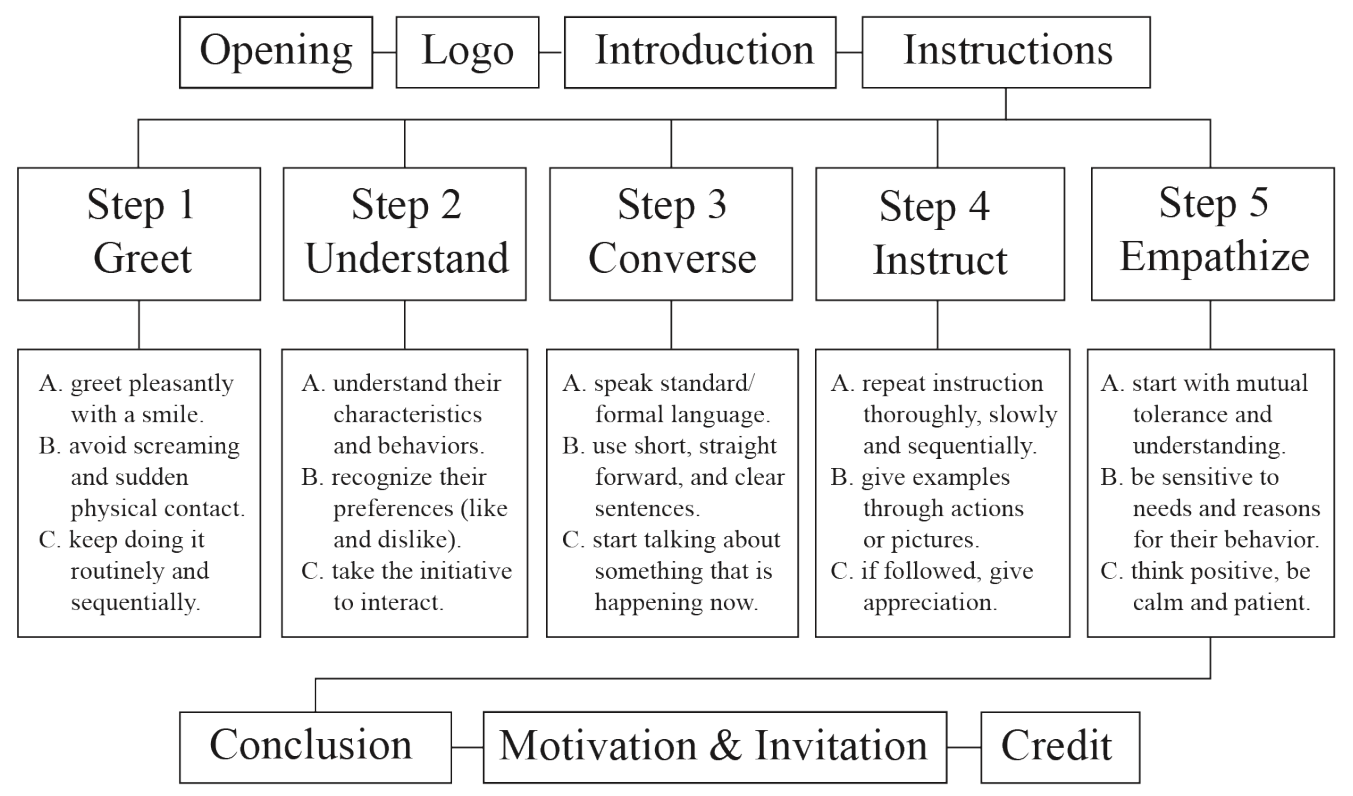

Figure 2: Motion Graphic Storyline

The name of this project, HAI! has two different meanings. First, the word itself is a familiar greeting word in Bahasa and is commonly used throughout Indonesia. Through this word, it is aimed to invite children in school age to develop their social skills from the simplest and easiest action like greeting. $\mathrm{HAI}$ is also an acronym of 'Hampiri Ajak Interaksi' which has persuasive meaning to take the initiative to approach and interact with people with autism. By doing that, both parties can practice and improve their communication and social skills while interacting with each other. As a result, it is expected that the effects of mutual development and growth will arise.

The resulted motion graphic was uploaded through social media, such as Facebook, Twitter, and Instagram, and website, such as Youtube as a video-content sharing platform and official website of autism associations, MPATI (Masyarakat Peduli Autis Indonesia) and YAI (Yayasan Autisma Indonesia). Video that was uploaded on YouTube has a long duration of around 2 minutes with complete content and five instructions. Meanwhile, videos on social media are short videos of about 30 seconds consisting of five series (each instruction was made separately). The reason of this strategy is the behaviour and time span of children on social media is different with video platform. 

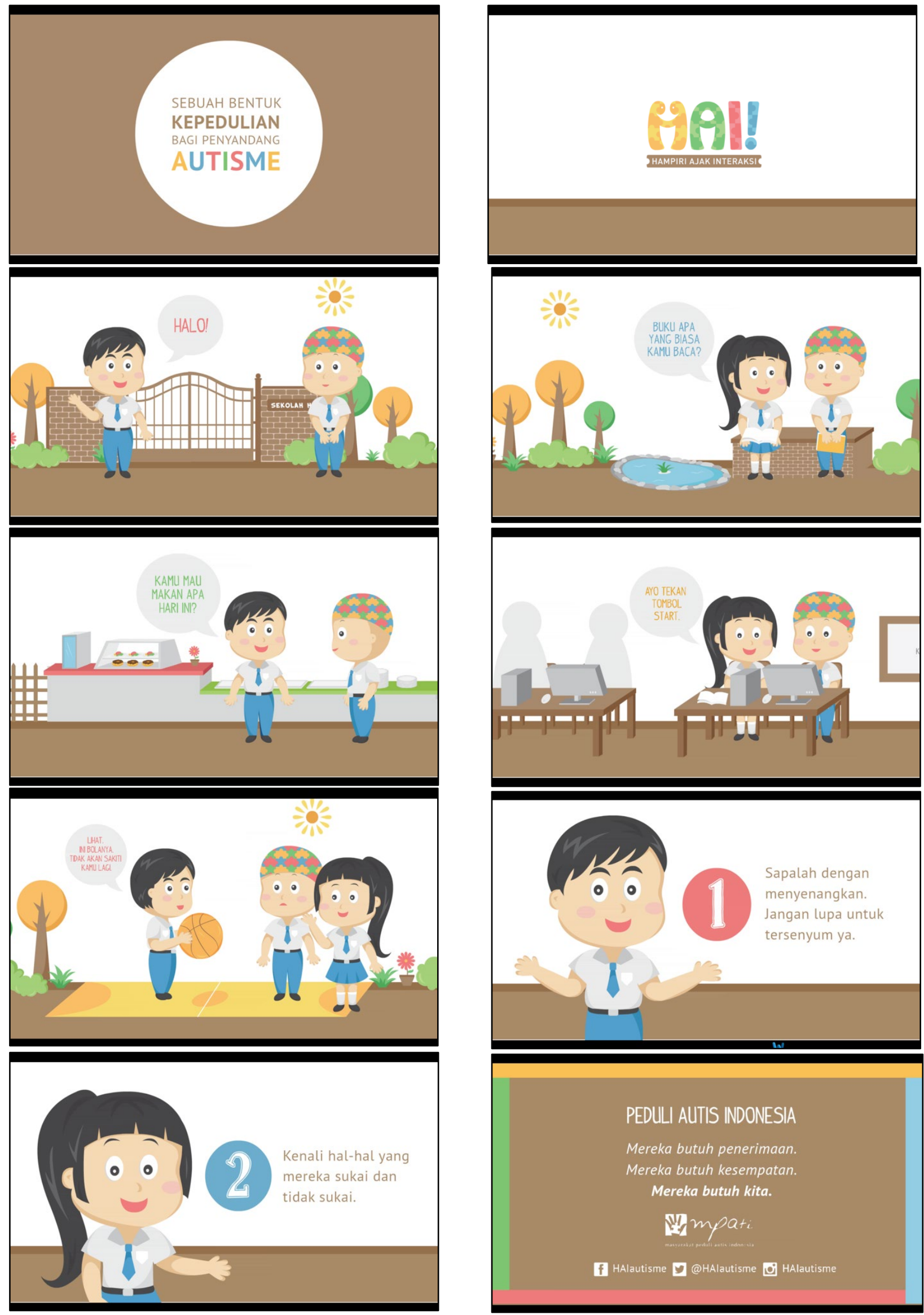

Figure 3: Motion Graphic HAl! 


\section{CONCLUSION}

HAI! project aims to increase public awareness and provide compatible practical instructions for grade schoolers in socializing with their high function autistic friends. Through this project, hopefully there is a positive change in the behaviour of students by not discriminating but instead begins to take the initiative to empathize and interact with people with autism with a more positive perspective. In other words, the focus is to dispel the misconception and mistreatment about autism so we can create a better environment for them in the near future. This project is a preliminary research to prove the potency and benefit of offering empirical approach about autism campaign. Therefore, it still has to be evaluated from various perspectives and refined to the more impactful version by expanding scale, media, and targets. Hopefully, this research can be improved and developed further to increase the level of engagement of people with autism on a higher extent.

\section{REFERENCES}

Autism Speaks. (2017). Autism and Health: A Special Report. Accessed 20 July 2019. https://www.autismspeaks.org/autism-facts-and-figures.

Caldwell, Phoebe. (2006). Finding You Finding Me: Using Intensive Interaction to get in touch with people whose severe learning disabilities are combined with autistic spectrum disorder. London : Jessica Kingsley Publishers.

Creswell, John W. (2014). Research Design: Qualitative, Quantitative, Mixed Methods Approaches. United States: SAGE Publications Inc.

National Autism Center. (2011). A Parent's Guide to Evidence-based Practice and Autism. Massachusetts : National Autism Center.

Rashid, Tallat. (2010). Developmental of Social Skills among Children at Elementary Level. Education and Research University of Education Pakistan 32 (1), 69-78.

Santrock, John W. (2011). Child Development: An Introduction. Dallas : McGraw Hills Humanities. 